\title{
MANAGING INNOVATION FROM AN EVOLUTIONARY PERSPECTIVE
}

\author{
CLARA-EUGENIA GARCÍA \\ Universidad Carlos III de Madrid
}

This special issue includes a set of four papers by M. Praest, S. Conway and F. Steward, P.P. Savioti and G.S.Mani, and P. Garrone and A. Rossini dealing with the management of technological innovation. The hallmark of these studies is that technological and organizational innovations are the primary drivers of business success and failure. However, the effort devoted to collect empirical evidence and to define the basic conceptual architecture for our understanding of innovation does not follow a single path. Most on-going research consists, essentially, of studying the development and diffusion of new technologies, the emergence of new organizational arrangements and the set of managerial practices and strategic visions that allow firms to create new capabilities and competencies as the way to sustain long-term performance and competitive advantages.

Different perspectives addressing a wide range of issues and dimensions often interrelated co-exist, and any distinction would be arbitrary since a few common themes run through most of the recent contributions. Hence, a major challenge rests on trying to provide a context and a coherent overview to innovation and its managerial implications at different levels. Current studies on technology management include the evolution of firms, sectorial patterns of technological development, the main sources of innovation used by firms in the development of their knowledge base, the factors influencing technological opportunities and threats faced by firms, and the internal technological, organizational and managerial processes influencing change. Notwithstanding the contributions on technology management the field has to undergo a major step in articulating how strategic management theories dealt with the several dimensions of innovation including both practical and theoretical concerns.

This special issue presents a set of valuable contributions that provide concepts, models, propositions and empirical evidence reflecting research-based knowledge. The papers included address the influence of micro behaviors on innovation patterns exhibit by organizations, the key factors underlying corporate success and failure, and the emergence of societal networks around technology development. However, the interdisciplinary charac-

Direct all correspondence to: Clara-Eugenia García, Department of Business Administration, Universidad Carlos III de Madrid. 
ter of the studies on innovation, the burgeoning of research in this field and the impact of country, industry, firm and technology specific features have added complexity to the task of editing a special issue such as this one.

The four contributions selected for this special issue on technology management (guestedited by Clara-Eugenia García of the Universidad Carlos III) all content references on the relevance of technology development for corporate vitality, but they also go beyond this general wisdom. They constitute valuable arguments in the analysis of innovation by addressing the role of the knowledge base of firms, how firms' competencies influence the set of strategic choices available to firms and the role of broader social and institutional networks fostering new technology development.

These contributions address a specific set of questions: How search efforts can be organized and crystallize around a different knowledge base? How much technology development and commercial success depend on social structures and the organization of social ties within the firm and among other institutional settings? How the relative position of firms based on their knowledge assets and complementarities influence investment decisions and the entry in new markets? How can be mapped the technological competencies of firms across different paths and what is the relationship between those technological competencies and the relative competitiveness of firms?

If further work on the subject would follow the conclusions made by the contributors, then European studies of innovation might converge around a more coherent theoretical framework grounded in evolutionary theories without abandoning neo-institutional approaches. In particular, the analysis of European firms and European data could be used to complement the view currently underway in the US were recent research on innovation shows little in the way of common theoretical underpinnings to guide its development. A dynamic knowledge-based view of firms adds considerably to incentive-governance considerations.

The critical task when editing this special issue has been to find an argument powerful enough to overcome the obstacles of reconciling conceptual and analytical differences. Despite, their variety and heterogeneity the contributions are framed around a set of core theoretical concepts emphasizing the dynamics of change, the embeddedness of technology and organizational innovations and, finally, the role of learning and of knowledge assets.

Research on management and innovation covered in this special issue finally converges around a few basic tenets. First, innovations in particular those that represent technological discontinuities appear in a space defined by external shocks but mainly constrained by endogenous learning processes. Second, learning emerges as the most remarkable feature of search and innovation and it takes place in specific cognitive and organizational settings. Third, innovation and learning issues are linked to the notion of social embeddedness introducing the role of collective, social and institutional structures as well as basic insights on the emergence and development of common cognitive models. Forth, innovation has a strategic dimension linked to the creation and exploitation of competitive advantages as result of the exploitation of resources' imperfect factor markets from which firms develop their competencies. Finally, innovation and its expected returns can not be isolated from uncertainty and risk taking capabilities exhibit by decision-makers; in spite of the unquestionable importance of innovation and technological change for survival some mangers still fail in recognizing technological opportunities and threats.

This special issue contains a set of complementary views reinforcing the idea that evolutionary perspectives can be improved hand in hand with organizational theories, strategic 
management and neo-institutional analysis. The papers are aimed at fostering these concepts as well as to separating the topical and fashionable from the enduring, the fads from the fundamentals. Furthermore, by editing this special issue we remain committed to the belief that management is not neutral in the development of innovations and technological change. Management does shape market positioning and learning trajectories and, consequently, it orients the knowledge accumulation and production.

Finally, it rest to mention that from the outset this special issue has two remarkable features; its multidisciplinary character capturing the richness of different research traditions and methods developed within innovation studies, and its European focus. In the pages that follow, the contributions made here have been ordered, for expository convenience, around the major themes covered.

\section{Technology Management and Technological Capabilities}

Technology has been an important, often critical, element in determining business competition and performance. Indeed, as innovation has increased its role becoming the major source of economic growth and entrepreneurial success demands new insights on the managerial and organizational aspects involved in this process.

In spite of recent theorizing attempts, the study of innovation has been linked, traditionally, to practical rather than theoretical concerns. Here, our experience suggests that in spite of firm, industry, technology and environmental characteristics we have to direct our efforts toward the building of an integrated conceptual framework leading to a better understanding of the complex set of interacting factors leading to innovation. In order to be able to face the challenges posed by the complex nature of change and innovation we believe that a coherent theory of organizational development and management is needed. Indeed, because the number of stories and cases reporting technological success and failure is countless empirical evidence has to be coupled with theoretical coherence.

The focal point of standard technology management is concerned with the elements that work in a specific business or market and how they affect a firm's performance. Specific issues such technological complexity and instability represented common themes of inquiry within macro strategic management approaches, together with market dynamism and competitive threats including resource availability and competition (Porter, 1980). In spite of major efforts devoted to understand the relationship between industry structure and strategic opportunities as a major source of competitive advantages, the usefulness of these macro approaches to technology management is doubtful (Barney, 1986a). Consequently, firms' organization and internal attributes are found to have a greater impact on success than critical competitive market factors (Barney, 1986b; Dierickx \& Cool, 1989). These internal attributes are referred to as resources and capabilities throughout current strategic management analysis. However, research on core competencies has been driven by theory building and it has largely contributed to an economic rather than managerial theory (Doz, 1997).

Resource-based theories of strategic management treat resources, capabilities and competencies as the components of inter firm differences accounting for differences in their competitive advantages, but what they are is only beginning to be the subject of serious theoretical and empirical investigations.

Thus, innovation has to be related and conceptualized as a process grounded on competence building and organizational dynamics. The development and redeployment of highly unique and valuable resources at the firm level has become the major theme of inquiry. 
Capabilities refer to the process and decisions related to the coordination, use and deployment of resources or input factors controlled by firms to develop their competitive advantages.

Resources and capabilities may be acquired in imperfect factor markets or built within the firm's boundaries (Mahoney \& Pandian, 1992), though some capabilities have a tacit and social nature. Differential access to knowledge and other critical factor inputs may be relevant to understand technological opportunities and threats faced by firms. For in resource-based theories core competencies and resources are tacit and cannot be traded (Prahalad \& Hamel, 1990). Often the firm's most valuable resources used in value creation are not only heterogeneous but they differ in the way the firm uses them according to the qualitative nature of its strengths and earlier experiences (Penrose, 1959). Consequently, private wealth and competitive advantages rest more on internal processes and less on conventional strategizing behavior.

This special issue contains two papers in such direction, representing an attempt to measure the impact of competencies and capabilities and to accurately define competencies, discuss some possible sources of its creation, maintenance, and variation, and sketch an approach to operationalizing them.

The paper by Paola Garrone and Andrea Rossini is aimed at analyzing and empirically testing the explanatory power of resource-based views of the growth of firms in the mobile telecommunication industry. The study covers sixteen European countries characterized, at the time data were collected, by the prevalence of monopolies in cellular telephony and the recent liberalization in mobile telecommunications. Then, the observed market power and leadership exhibited by domestic telephone companies have been explained by the effect of three major economic factors: market power, static efficiency and dynamic capabilities of firms grounded on idyosincratic assets or resources.

The findings reported provide support for the effect of the latter, particularly for the role that technological, product and market competencies play in business diversification. Consequently, even in a market in which government exclusive concessions has a significant impact, entry and diversification decisions made by companies rest on their ability to achieve efficient coordination and exploitation of technological, product and market capabilities rather than on temporary monopoly benefits. Hence, competitive advantages might be linked to the strategic use of specific knowledge and intangible resources with greatest rent potential.

Finally, the paper by Garrone and Rossini contents some valuable insights on how ownership structures can be interpreted from a resource-based view. At its best, resource-based theories make a useful distinction between the generation of valuable resources and capabilities, and whether the proper vehicle for rent-generating activities is a vertically integrated firm or independent firms, allowing for the emergence of strategic interaction.

In spite of its important insights, resource-based theories have neglected the relevance of the properties of resources to account for firm' s heterogeneity and enduring differences. The paper by Mette Praest is devoted to clarify such issue and to offer a more elaborated distinction between resources, assets, competencies and capabilities.

Resources are mainly referred, as noted above, as key input factors and, consequently firms' might enjoy economic rents from the exploitation of imperfections in the markets from which they obtain such factors. Moreover, asymmetries between resource market imperfections and decisions about resource selection lead the firms to differ in their resources (Amit \& Schoemaker, 1993; Oliver, 1997). The author, further claims that a firm's resources are hierarchically organized according to the value of the knowledge 
inherent in the firm (intangible assets) and the internal value of the assets possessed by the firm (tangible assets). In contrast, competencies represent the ability to solve problems and make decisions in a specific organizational setting. Finally, unlike competencies that are shaped by the organizational context, capabilities represent very specific abilities in the use of a particular type of resources to create value and increase performance.

Finally, the paper by Mette Praest represents an interesting attempt to measure technological capabilities based on patent analysis and to map changes registered in the technological capabilities of firms acting simultaneously in different technological fields. While several limitations to the use of patent data apply, the exploratory analysis presented here shows the fruitfulness of her exploratory exercise.

Resource-based views stress the idea that resource's markets imperfections lead to increasing heterogeneity, which is at the base of differential economic rents and competitive advantages. However, the strength of resource-based views in the management of innovation emanates from three basic features. First, it provides a plausible and compelling story that identifies the causal mechanisms linking economic organization to the set of managerial capabilities to coordinate a vast and heterogeneous set of resources and capabilities. Second, the organization and management of innovation, and decisions related to the resource selection processes, and competencies' development, may have a positive, negative or neutral effect on rent-generating activities.

Notwithstanding these arguments, resource-based perspectives unlike economic evolutionary theories of innovation lack of any assumption concerning the behavioral patters of individuals and organizations, that may upset the gains from the acquired resources and capabilities. And third, they might generate a testable theory applicable to cases in which complementarities within sets of competencies differ across firms according to (a) the specific characteristics of their key resources and (b) the different set of complementary competencies develop as firms aim catering to different market segments. Consequently, firms differ in their ability to coordinate and integrate diverse production skills and multiple streams of technologies while the acquisition, selection and management of resources may also be constrained by complementary assets developed over time that lead firms to the appropriation of organizational rents.

Before going any further in the analysis of the literature, it is important to call attention on the essential role of learning within evolutionary theorizing. Learning effects by the means of search might increase variety representing a change in the probability distribution of possible actions in problem solving setting. In the other hand, learning effects by the means of exploitation of acquired organizational routines and technological capabilities provide the basis for holding variety relatively constant as required for selection mechanisms to operate.

Knowledge-based theories of innovation refer to firms' idyosincratic resources and the dynamics of learning as crucial drivers of change. One of the distinctive features of the evolutionary thinking underlying recent contributions in the economics of technical change is that innovation is susceptible to some degree of intentional management. Management involves individual and organizational learning in a dynamic context. Thus, while learning might introduce variety by the means of adaptation, learning is also constrained by organizational design and other organizational factors. The organization may, or may not, adopt itself the favored shape, it has just a few options available that will increase fitness and many that would make things worse; an organization can only change its actions to a certain degree and it cannot make large jumps. 


\section{Technology, the Knowledge Base of Firms and Search Behavior}

The variegated nature of the analysis on innovation and technological change clearly reflects different research traditions that cannot be integrated around a dominant theoretical perspective (Drazin \& Schoonhoven, 1996). In the last decade new thinking on innovation and technological change has been fostered by a wave of evolutionary theorizing in economics (Nelson and Winter, 1982), and strategic management (Teece, Pisano \& Shuen, 1997).

Traditionally, technology management has been concerned with the study of the set of practices and business actions leading to technology development and its successful commercialization. However, while technologies themselves may be seen as evolving they are not isolated and selected in a pure technological space but incorporated within business organizations. Therefore, one still needs some theory of organizational development to understand the role, nature and emergence of those practices.

It is an unavoidable fact that any attempt to build a new framework or theoretical breakthrough opens up a battery of questions. Evolutionary perspectives seek to explain at different levels of analysis dynamic time paths, or how technologies, organizations and practices change over time in ways that are not deterministic.

Innovation theories postulating evolutionary models distinguish between very different types of innovation: radical innovations, technological discontinuities, and gradual innovations. The concept of gradual innovations, clearly articulated around Lamarckian theories of evolution, refers to the progressive transformation of technologies from one condition to another as adaptation through different mechanisms takes place. This vision framed within a knowledge based view of firms leads to the consideration that search activities do not depart significantly from previous knowledge accumulated within a particular technological field or organizational setting. In spite of it, a new concept of innovation has been introduced based on the generation of a new knowledge base and an entirely new pool of technological capabilities and routines. In such context, innovations emerge representing new technological paradigms, discontinuities or dominant designs. Hence, such types of innovations depend on knowledge accumulation and the dynamics of learning effects by the means of search.

Technological transitions are not always easy to interpret while their existence is so strongly supported by facts. The paper by Saviotti and Mani represents an attempt to find an evolutionary theoretical explanation for the existence of technological regimes and discontinuities given the general features of knowledge, learning dynamics and technological populations.

The argument, thus, is not whether search efforts are translated into knowledge creation, but rather whether they lead to the development of new competitive and successful products and technologies representing entirely new types of solutions. In order to advance the theoretical underpinnings of these paradigmatic changes, the authors claim the appealing and usefulness of nucleation theory which is used to explain fluctuations within a stable population of technologies because of the existence of technological barriers to overcome in order to experience a radical shift.

The paper focuses in the dynamics and life cycle of search efforts, described by means of their range and their probability of success. The general hypothesis asserts that well-established technologies usually evolve gradually by means of search efforts, however, search efforts departing from such well-established technologies may lead to rapid technological and evolutionary transformations. Whenever search activities lead to a new technological 
setting defined in a complete new space such technology will represent a radical innovation.

This paper holds that the firm's level of search efforts will depend on the size of existing and potential markets, the level of competition, the differential expected advantage of the new technologies and, finally, the probability of success in the development of new technologies. Moreover, firms are expected to engage in search efforts, required to develop of a complete new knowledge base and to overcome the technological barriers, because the new technology will exhibit higher fitness than the old one.

The theoretical model used here focuses on the dynamics of search efforts when applied to two technological populations exhibiting differential capabilities to adapt to the external environment. Hence, any shift from the pre-existing technological setting to the new one will imply high levels of investment in search efforts, that are expected to be proportional to the distance between the two technological spaces according to their technical characteristics. Finally, search efforts devoted to technological innovation will depend on the rate of learning of a given technology and on the opportunities of the technology itself.

The authors build a model based upon the existence of a life cycle of search efforts. Accordingly, search efforts are likely to grow as the new technological population increases its density. The rate of investment in search will decrease gradually during the life cycle of the technology. In other words, the rate of search will be low at the early stages of the new technological development because of uncertainty. Search will increase gradually in order to overcome the technological barrier between the pre-existing knowledge base and the new one required, and will be higher as it becomes more applied and focused. Finally, search it is expected to slow down as the technological opportunities become exhausted.

The authors clearly model an artificial transition that produces a new technological setting. We must recognize, however, that only a small fraction of search efforts undertaken by firms yield to a completely new technological setting. Clearly, many local search efforts that may end up in new technological settings die out. Finally, it is worth noticing that search activities and learning dynamics leading to technological transitions are shaped by the asymmetrical distribution of returns to old and new technologies and they are time dependent. The model proposed here may be enlarged and it can be used to related technology cycles and search cycles to changes in firm and industry structures as papers from a different tradition have shown (Afuah \& Utterback, 1997). Hence, cumulative learning and competency's development constraint industry evolution but their main effects cannot be captured until dominant paradigms or designs emerge.

\section{The Social and Institutional Embeddedness of Technology}

The evolutionary processes and dynamics of innovation discussed above proceed in an organizational setting, however, business organizations are not isolated entities; they operate, interact and learn in a changing and plastic external environment. It is nowadays generally acknowledge that change, innovations and technological development are not independent. A large body of empirical studies suggests that the institutional environment in which organizations operate largely shape the outcomes and the rate of success and failure. Basically, collective action by private and public actors matters, and the outcomes of innovative activities are greatly conditioned by the political, regulatory and social environment. 
Traditionally, changes in technologies, practices, and products have been described in terms of their relative success. Many of these innovation stories have been aimed at identifying the individual and idyosicratic features underlying them. Departing, significantly from this view, there is a long tradition in investigating the inter-organizational networks within and between sectors, regions and countries that have fostered innovation and knowledge production (Hakansson, 1989; Hagedoorn \& Schakenraad, 1992). From this research the traditional linear models of innovation have been displaced and the interactive model of innovation has being to emerge. Therefore, innovation is an interactive and iterative process in which actors weave a seamless web of both social and technical elements including the set of actors, relationships and flows drawn upon in the development of discrete innovations.

Grounded in this tradition, the paper by Steve Conway and Fred Stewart focuses on the complex external environment in which firms operate and how it shapes the development of new technologies. This paper is based in a set of underlying assumptions drawn from the management of technology and the social studies of science traditions.

Recent innovation studies have focused in analyzing the specific capabilities that led to technological performance, and on the sources of key input factors, customers and suppliers relationships and their role in stimulating innovation and managing problem-solving activities. In contrast, the sociology of science has provided a riche body of research concerning the social structure of scientific communities and, what is of major interest in management, they have adopted a relational approach aimed at providing an integrated view on both structure and relationships (Burt, 1982). Hence, technological success can better be explained by the analysis of the concrete interpersonal and organizational relations in which actors engage in innovation are embedded.

The authors have collected empirical evidence on the development of environmental technologies in Germany and the United Kingdom to test the robustness of technologies as a function of their societal embeddeness. Their findings show that often a technological choice is a social choice since technologies embody a set of hypothesis concerning the characteristics of the context in which the have to function. Altogether, the generation of innovation does not respond directly to autonomous strategic behavior exhibit by firms. Technology development and further commercial success will be a function of a dense network in which multiple actors play a role simultaneously.

The paper is aimed at explaining how some of the differences in technology development and performance might be related to the specific environments, sectorial, technological and social settings in which innovation takes place. This notwithstanding, the authors show that the two countries examined display differences in their networking patterns concerning the development of environmental technologies. Consequently, some of the differences in the formation and working of focal innovation action sets might explain differences in the technological path. Hence, technological performance will be rewarded by the strength and functioning of such societal networks rather than pure market factors and firm technological capabilities.

Environmental technologies have emerged in specific networks based on the relationship between producers, suppliers, governmental bodies, regulatory pressures, consumers and a vast set of actors. The most fundamental and strategic factor within the successful development of new technologies is the nature of ties within such complex networks in which the common and divergent interests represent a mixture of conflict and cooperation. 
The results provided suggest that firms will be more likely to create and sustain competitive advantages if they build and operate in interactive networks rather than individual technological capabilities and adapt to external contingencies.

\section{SUMMARY}

I began this introduction by describing how research on innovation and management conducted in the last decade lacks of a dominant and unifying theoretical perspective. Moreover, both strategic management and studies on innovation have been subject to major transformations and internal debates. At the level of strategic management major emphasis has been placed to the analysis of external opportunities and competitive threats based up on market and industry characteristics while firm's characteristics was thought as a blueprint helping to define its relative competitive position. In the mean time, research on innovation, and in particular, the economics of technical change, has experienced a major transformation from the building of equilibrium models to exploring alternative ways to explain empirical phenomena that deal with nonlinear dynamic systems.

A key idea running through the different papers published in this special issue is that research on different aspects of innovation requires the combination of modern theories of the firm and adaptation while the locus and structure of decision making remains a critical factor. Indeed, some emphasis has been placed recently on the role of strategic decisions concerning innovation patterns. Hence, new insights from resource-based theories within strategic management can be fruitful combined with new evolutionary models within economics (Dosi, Teece \& Chytry, 1998).

Firms play the most significant role in the innovation process; they are the primary actors in the production of new technologies and the imitation of the old ones, but they influence the external environment in which they compete through their strategic actions. Indeed, technology represents but one of the critical variables in firm's competitiveness and corporate survival. Consequently, corporate visions and decision rules such as investment, $R \& D$ focus, pricing policies, diversification and so forth have a major role in the evolution of technologies. From an evolutionary point of view business organizations are continuously forming hypotheses about the environment they face, and the strategies and actions of their competitors in order to reduce uncertainty, and increase its subjective probability of fitness i.e. competitiveness.

In addition, technological change and the challenges faced by innovation management originate in the complexity of interdependent choices; they can not be reduced to problems of choice under asymmetric information. From this perspective, technological options and decisions emerge in a context that is far from satisfying the required conditions for rational and deliberative decision making or the requirements for strategizing behavior (Garud, Nayyar \& Shapira, 1997).

Through the selected papers contained here technology will emerge as having a life in its own but also as the outcome of individual -firm level, and collective action -institutional framework. Hence, one of the most relevant conclusions is that technology can be managed but not fully controlled. Moreover, in this introductory overview I have also stated that managerial decisions concerning innovation and technological development are strongly influenced by a lack of robust knowledge concerning environmental representations. Unforeseen consequences and environmental effects are products of micro-behaviors, mac- 
roeconomic processes, social influences and random events. Hence, the result is neither deterministic nor only a matter of deliberative and strategic choice.

Because the path of innovation is complex, and its management has to take such complexity into account. It includes investment in search activities that will be a function of pre-existing technologies and their technological opportunities as well as of market demand, competitive advantages of new technologies, and so on. Moreover, the complexity of technology management has to be understood not only as the selection process of critical factor inputs or resources but the way to support and sustain the development of individual and collective abilities to foster learning within specific organizational settings. The management of technology has to take also into account that technology development has both a technical and a social dimension, with feedback and cumulative causation.

\section{ACKNOWLEDGMENTS}

This special issue contents a selection of papers presented at the Conference on Management and New Technology, held in Madrid in June 1996 and organized under the auspices of the European Commission (Cost A3 Action). The proceedings of the Conference were published by the European Commission in 1997 and edited by Clara-Eugenia García and Luis Sanz.

Acknowledgements and gratitude is devoted to the authors who's contributions have made possible this special issue and the list of participants in the Conference, without their dedication, effort and interest this special issue would never be possible. I wish to acknowledg specially the generous help of Luis Sanz with the organization of the Conference and his helpful comments on this brief introductory section.

\section{REFERENCES}

Afuah, A. N., \& Utterback, J. M. (1997). Responding to structural industry changes: A technological evolution perspective, Industrial and Corporate Change, 6, 183-202.

Amit, R., \& Schoemaker, P. J. H. (1993). Strategic assets and organizational rents, Strategic Management Journal, 14, 33-46.

Barney, J. B. (1986b). Strategic factor markets: Expectations, luck, and business strategy, Management Science, 32, 1231-1241.

Barney, J. B. (1986a). Organizational culture: Can it be a source of sustained competitive advantage? Academy of Management Review, 11, 656-665.

Burt, R. S. (1982). Toward a structural theory of action: Network models of social structure, perception and action, New York: Academic Press.

Dierickx, I. \& Cool, K. (1989). Asset stock accumulation and sustainability of competitive advantage, Management Science, 35, 1504-1511.

Dosi, G., Teece D. J., \& Chytry, J. (Eds), (1998). Technology, organization and competitiveness. Perspectives on industrial and corporate change, Oxford, New York: Oxford University Press.

Doz, I. (1997). Managing core competency for corporate renewal: towards a managerial theory of core competencies. In A. Campbell, \& K. Sommers Luchs (Eds.), Core competency based strategy. London: International Thomson Business Press, 53-75.

Drazin, R., \& Schoonhoven, C. B. (1996). Community, population, and organization effects on innovation: A multilevel perspective, The Academy of Management Journal, 39, 1065-1083. 
Garud, R., Nayyar, P., \& Shapira, Z. (1997). Technological choice and the inevitability of errors. In R. Garud, P. Nayyar, \& Z. Shapira (Eds) Technological innovation. Oversights and foresights. New York: Cambridge University Press, 20-40.

Hagedoorn, J., \& Schakenraad, J. (1992). Leading companies and networks of strategic alliances in information technologies, Research Policy, 21, 163-190.

Hakansson, H., (1989. Corporate technological behaviour: Co-operation and networks, London: Routledge.

Mahoney, J. T., \& Pandian, J. R. (1992). The resource-based view within the conversation of strategic management, Strategic Management Journal, 13, 363-380.

Nelson, R. R., \& Winter, S. G. (1982). An evolutionary theory of economic change, Cambridge, Mass.: The Belknap Press.

Oliver, C., (1997). Sustainable competitive advantage: Combining institutional and resource-based views, Strategic Management Journal, 18, 697-713.

Penrose, E., (1959). The theory of the growth of the firm. London, New York: Oxford University Press, Revised edition 1995.

Porter, M. E., (1980). Competitive strategy, New York: The Free Press.

Prahalad, C. K., \& Hamel, G. (1990). The core competence of the corporation, Harvard Business Review, 82, 79-91.

Teece, D. J., Pisano, G., \& Shuen, A. (1997). Dynamic capabilites and strategic management, Strategic Management Journal, 18, 509-533. 